Proceedings of the ASME Turbo Expo 2012: Power for Land, Sea and Air

June 15-19, 2011, Copenhagen, Denmark

\title{
GT2012-69639
}

\section{JET-SURFACE INTERACTION TEST: FAR-FIELD NOISE RESULTS}

\author{
Clifford Brown \\ NASA Glenn Research Center \\ Cleveland, Ohio, USA
}

\section{ABSTRACT}

Many configurations proposed for the next generation of aircraft rely on the wing or other aircraft surfaces to shield the engine noise from the observers on the ground. However, the ability to predict the shielding effect and any new noise sources that arise from the high-speed jet flow interacting with a hard surface is currently limited. Furthermore, quality experimental data from jets with surfaces nearby suitable for developing and validating noise prediction methods are usually tied to a particular vehicle concept and, therefore, very complicated. The Jet/Surface Interaction Test was intended to supply a high quality set of data covering a wide range of surface geometries and positions and jet flows to researchers developing aircraft noise prediction tools. During phase one, the goal was to measure the noise of a jet near a simple planar surface while varying the surface length and location in order to: (1) validate noise prediction schemes when the surface is acting only as a jet noise shield and when the jet/surface interaction is creating additional noise, and (2) determine regions of interest for more detailed tests in phase two. To meet these phase one objectives, a flat plate was mounted on a two-axis traverse in two distinct configurations: (1) as a shield between the jet and the observer (microphone array) and (2) as a reflecting surface on the opposite side of the jet from the observer. The surface was moved through axial positions $2 \leq \mathrm{x}_{\mathrm{TE}} / \mathrm{D}_{\mathrm{j}} \leq 20$ (measured at the surface trailing edge, $\mathrm{x}_{\mathrm{TE}}$, and normalized by the jet diameter, $\mathrm{D}_{\mathrm{j}}$ ) and radial positions $1 \leq \mathrm{h} / \mathrm{D}_{\mathrm{j}} \leq 20$. Far-field and phased array noise data were acquired at each combination of axial and radial surface location using two nozzles and at 8 different jet exit conditions across several flow regimes (subsonic cold, subsonic hot, underexpanded, ideally expanded, and overexpanded supersonic cold). The far-field noise results, discussed here, show where the surface shields some of the jet noise and, depending on the location of the surface and the observer, where scrubbing and trailing edge noise sources are
\end{abstract}

created as a surface extends downstream and approaches the jet plume.

NOMENCLATURE

AAPL Aero-Acoustic Propulsion Laboratory

AI-OASPL Arc Integrated-Overall Sound Pressure Level BBSN Broadband Shock Noise

SHJAR Small Hot Jet Acoustic Rig

$\mathrm{R}$

$\mathrm{D}_{\mathrm{j}}$

$\mathrm{f}$

$\mathrm{St}_{\mathrm{Dj}}$

$\mathrm{x}_{\mathrm{TE}}$

$\mathrm{h}$

line to the surface

$\mathrm{P}_{\mathrm{a}} \quad$ ambient pressure

$\mathrm{T}_{\mathrm{a}} \quad$ ambient temperature

$\mathrm{c}_{\mathrm{a}} \quad$ speed of sound at ambient conditions

$\mathrm{P}_{\mathrm{j}} \quad$ jet total pressure

$\mathrm{T}_{\mathrm{s}} \quad$ jet static temperature

$\mathrm{c}_{\mathrm{j}} \quad$ speed of sound at local jet conditions

$\mathrm{v}_{\mathrm{j}} \quad$ jet velocity

$\mathrm{v}_{\text {id }} \quad$ ideally expanded jet velocity

$\mathrm{M}_{\mathrm{a}} \quad$ acoustic Mach number, $\mathrm{M}_{\mathrm{a}}=\mathrm{v}_{\mathrm{j}} / \mathrm{c}_{\mathrm{a}}$

$\mathrm{M}_{\mathrm{j}} \quad$ local jet Mach number, $\mathrm{M}_{\mathrm{j}}=\mathrm{v}_{\mathrm{j}} / \mathrm{c}_{\mathrm{j}}$

$\mathrm{M}_{\mathrm{id}} \quad$ ideally expanded jet Mach number, $\mathrm{M}_{\mathrm{id}}=\mathrm{V}_{\mathrm{id}} / \mathrm{c}_{\mathrm{j}}$

NPR nozzle pressure ratio, $\mathrm{NPR}=\mathrm{P}_{\mathrm{j}} / \mathrm{P}_{\mathrm{a}}$

$\mathrm{U}_{\mathrm{j}} \quad$ jet exit velocity

$\mathrm{U}_{\mathrm{c}} \quad$ local jet convection velocity

$\mathrm{x}_{\mathrm{W}} \quad$ Witze correlation parameter

\section{INTRODUCTION}

Many current and future aircraft designs place the jet engine exhaust in close proximity to the surfaces of the airframe. The engine under wing design, for example, which is common in the current civilian fleet, has a jet exhaust that is 1

This work is declared a work of the U.S. Government and is not subject to copyright protection in the United States. Approved for public release; distribution is unlimited. 
around the pylon that holds the engine below the wing, near the underside of the wing itself, and directly into the wing flaps when they are deployed. When the high-speed jet flow interacts with these surfaces, either by passing along them or striking them more directly, additional noise is created. Future aircraft concepts, such as the blended wing body, often attempt to use the airframe surfaces as a noise shield to block the engine exhaust noise from people on the ground. In both configurations, the ability to accurately predict the noise created or shielded by interactions between the jet flow and the airframe surfaces is critical to reducing the overall noise produced by the aircraft. However, modern jet noise prediction methods were generally developed to predict the noise of an isolated jet and are not applicable when the aircraft surfaces are included in the prediction. Furthermore, quality experimental data covering a range of jet conditions and surfaces suitable for developing and validating jet-surface noise prediction methods are limited. The Jet-Surface Interaction Test was envisioned to supply experimental data covering a wide range of surface geometries and jet flows to improve and validate the current generation of aircraft noise prediction tools.

The NASA Fundamental Aeronautics Program's Subsonic Fixed Wing Project, Airport Noise element is tasked with developing technologies to mitigate the impact of aircraft noise on the environment near airports. Aircraft deigns that rely on the airframe surfaces to shield people on the ground from the jet engine noise are being explored for the next generation of aircraft. However, development of these future airplanes would benefit from more accurate jet-surface interaction noise prediction methods that allow for any configuration. The Jet / Surface Interaction Test is being supported by the Subsonic Fixed Wing Project to assist the creation and improvement of noise prediction tools that will ultimately help design the next generation of aircraft.

The presence of a hard surface in the proximity of a turbulent jet results in an augmentation of low frequency noise above that expected from a similar isolated jet. This augmentation is called jet-surface interaction noise and may be broadly described by two separate source mechanisms: flow 'scrubbing' noise and surface trailing edge noise. However, because both noise sources are generated by the convecting turbulent jet flow and are dipolar in nature, they have similar spectral characteristics and are often difficult to separate into individual components [1]. This strict definition of jet-surface noise, which deals only with the noise sources, may be expanded to include the directly related problem of sound propagation around the surface to the far-field. These reflection and shielding effects are shown in Figure 1 along with the jetsurface interaction noise.

A considerable amount effort has been made to build a theoretical framework to describe these jet-surface interaction noise sources. Curle first showed via a modification to Lighthill's analogy that the jet-surface noise could be expressed as a distribution of dipole sources on the surface [2]. This extension to Lighthill's equation is exact and may include surface deflection effects and sound reflection in the source terms. A dimensional analysis of the equations showed that the far-field sound level related to a jet travelling along a surface scales with the convection velocity $\left(U_{c}\right)$ as $U_{c}{ }^{6}$. At the trailing edge of the surface, however, the length and velocity scales may be given by the surface geometry rather than the turbulence, giving rise to the trailing edge noise source. Ffowcs Williams and Hall addressed this problem for a rigid semiinfinite surface and were able to show that the sound generated by turbulence close to the edge (trailing edge noise) is more intense than the sound generated by a similar turbulent flow in free space [3]. Furthermore, if the surface is rigid, which may be assumed in most aircraft applications, then the trailing edge noise source scales as $\mathrm{U}_{\mathrm{c}}{ }^{5}$. Crighton and Leppington expanded this work to show that the scaling exponent varies between 5 and 6 depending on the relative stiffness of the surface [4]. Later research by Chase [5] and Amiet [6] modified these theories to use the convecting surface pressure upstream of the trailing edge as a basis to determine the strength trailing edge noise source. More recently, Large Eddy Simulations have been used with Ffowcs Williams-Hawkins methods to predict jetsurface noise [7, 8]. Some attention has also been given towards developing empirical models for the jet-surface shielding effect based on the experimental data available that could be used in system studies (see [9] for example).

Experimental data acquired over many years have generally supported (or helped develop) these jet-surface interaction noise theories. Chase used experimental data to develop a model for the surface pressure and validate it against some far-field noise measurements [10]. Head and Fisher used experiments to show that the jet-surface noise source is dipolar and to study the shielding effects of the surface [11]. Brooks and Hodgson evaluated several theories for the case of a twodimensional airfoil [12] while Howe considered experimentally how the shape of the trailing edge influences the noise created $[13,14]$. More recently, Mayoral and Papamoschou have used experiments to study the potential for increasing jet noise shielding by redistributing the noise sources via chevron nozzles [15] and to examine jet noise shielding in a hybrid wing-body aircraft [16], Hutcheson and Brooks considered the effect of angle of attack on trailing edge noise [17], and Lawrence et. al. [1] acquired near- and far-field data for a round jet near a flat surface to validate Amiet's trailing edge noise prediction method and the classically derived scaling exponents. The current Jet-Surface Interaction Test is an effort to build on these experiments to cover a wider range of surface positions, jet flow conditions, and, in future phases, geometries.

The Jet-Surface Interaction Test will be conducted in several phases. The goals for phase one are (1) to acquire farfield and phased array noise data for the simple case of a flat plate near a round single stream jet acting as a noise shield, a noise reflector, and as a noise source, and (2) to determine "regions of interest" for future phases. It should be noted here that the range of surface lengths and positions goes far beyond any likely to be on an aircraft to ensure that each type of jet surface interaction (e.g. surface in flow and out of flow) is represented in the data base. In addition to varying the surface

2

This work is declared a work of the U.S. Government and is not subject to copyright protection in the United States. Approved for public release; distribution is unlimited. 
positions, data are acquired in four different jet flow regimes: subsonic, ideally expanded supersonic, overexpanded supersonic, and underexpanded supersonic. The resulting data set retains the geometric simplicity for easier implementation in noise prediction codes (e.g. building grids) but introduces complexity though surface position and jet flow regime. For example, development of a noise prediction method might begin with a noise propagation problem where the surface is outside a subsonic jet plume and progress to a configuration with the same jet flow but where the surface is inside the jet plume adding the jet / surface interaction noise sources to what was just a noise propagation problem. Improvements from this point could focus on hot subsonic jets or move toward supersonic jets with or without shocks. The far-field noise data are discussed here and the phased array results may be found in [18].

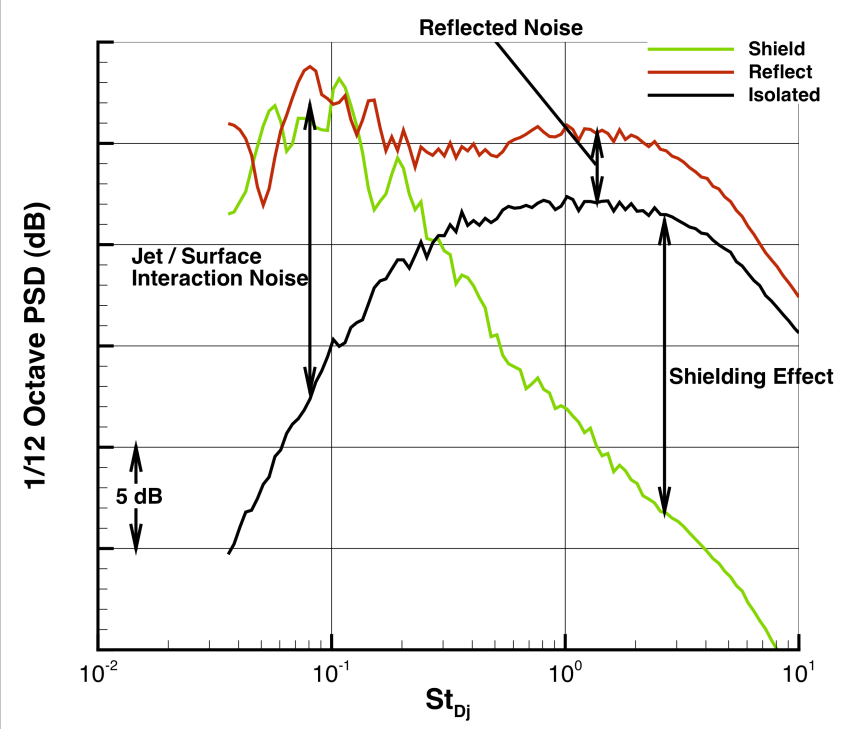

Figure 1: Spectral changes as a function of Strouhal frequency $\left(\mathrm{St}_{\mathrm{Dj}}\right)$ attributed to jet / surface interaction noise, reflected noise, and shielded noise when a flat plate is added to an isolated jet. Data were acquired with the plate at $\mathrm{x}_{\mathrm{TE}} / \mathrm{D}_{\mathrm{j}}=15, \mathrm{~h} / \mathrm{D}_{\mathrm{j}}=1$ and using $\mathrm{a} \mathrm{M}_{\mathrm{a}}=0.9$, cold jet.

\section{TEST PLAN, SETUP, AND DATA PROCESSING}

The test was conducted at the NASA Glenn Research Center (GRC) in the Aero-Acoustic Propulsion Laboratory (AAPL) using the Small Hot Jet Acoustic Rig (SHJAR, Figure 2). The SHJAR is capable of supplying a single-stream nozzle with air heated up to $1300{ }^{\circ} \mathrm{F}$, using a hydrogen burning combustor, at flow rates up to $6 \mathrm{lbm} / \mathrm{s}$. Flow conditioning and a line-of-sight muffler are used to create a clean quite flow down to a jet exit Mach number of $M_{a}=0.35$. More information on the SHAJR, along with performance validation data for noise measurements, can be found in references [19] and [20].
The geometry tested during the Jet-Surface Interaction Test consisted of a round nozzle and a flat plate using the geometry shown in Figure 3. The plate was mounted on an automated traverse system, moving in the radial direction, with a range from $h / D_{j}=1$ to $h / D_{j}=16$. The radial traverse was mounted on rails so that it could be moved manually in the axial direction. The plate was made using a $1 / 2$ " thick aluminum cut into sections that could be added or removed to change the length of the surface. This allowed testing of 6 different surface lengths ranging from $\mathrm{x}_{\mathrm{TE}} / \mathrm{D}_{\mathrm{j}}=2$ to $\mathrm{x}_{\mathrm{TE}} / \mathrm{D}_{\mathrm{j}}=20$. Medium duty welding blankets were used to form a curtain behind and upstream of the aluminum plate so that sound could not pass between the surface and the jet rig even as the surface moved to different locations. The integrity of this arrangement was verified by both far-field and phased-array measurements. Figure 4 shows each radial and axial surface position tested during phase one of the Jet-Surface Interaction Test. Note that data were acquired for each combination of radial and axial surface position with the surface in both the shielded and reflected position for a total of 204 different surface locations.

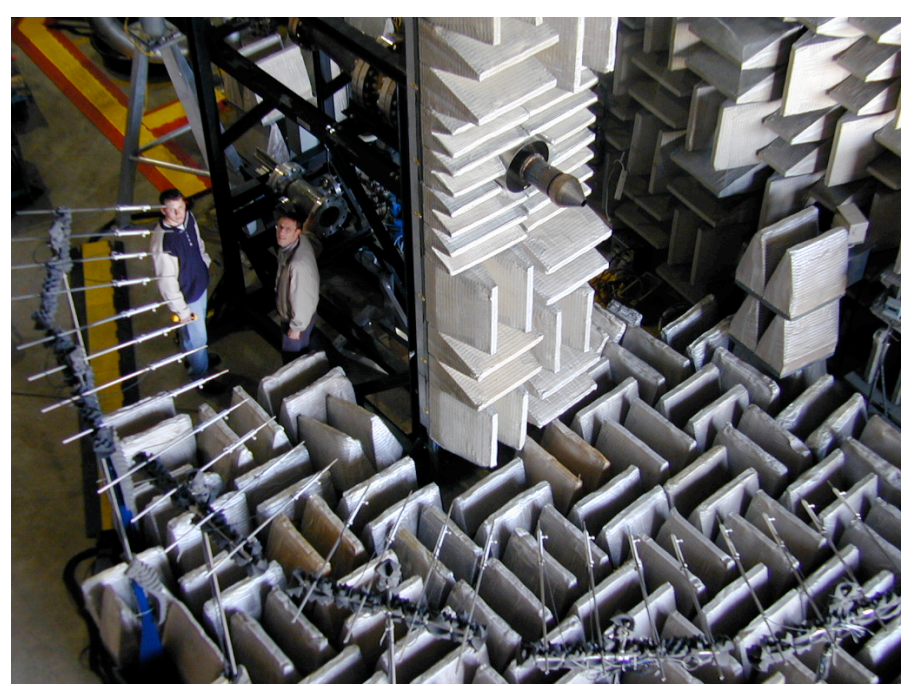

Figure 2: The Small Hot Jet Acoustic Rig (SHJAR) located in the Aero-Acoustic Propulsion Laboratory (AAPL) at the NASA Glenn Research Center (GRC) shown in acoustic configuration with the 24-microphone array located on a 150 -inch radius arc centered on the nozzle exit.

The trailing edge of the surface was made from $1 / 4$ " aluminum sheet and angled at approximately $40^{\circ}$ on side opposite the flow to make a point (Figure 5). The same trailing edge piece was used for all plate lengths to ensure consistency across all configurations. Furthermore, all of the attachment hardware was placed on the back of the plate so the flow side was smooth. The mounting rails and attachment hardware where also covered by acoustic foam to minimize any sound reflection from the back of the plate. 


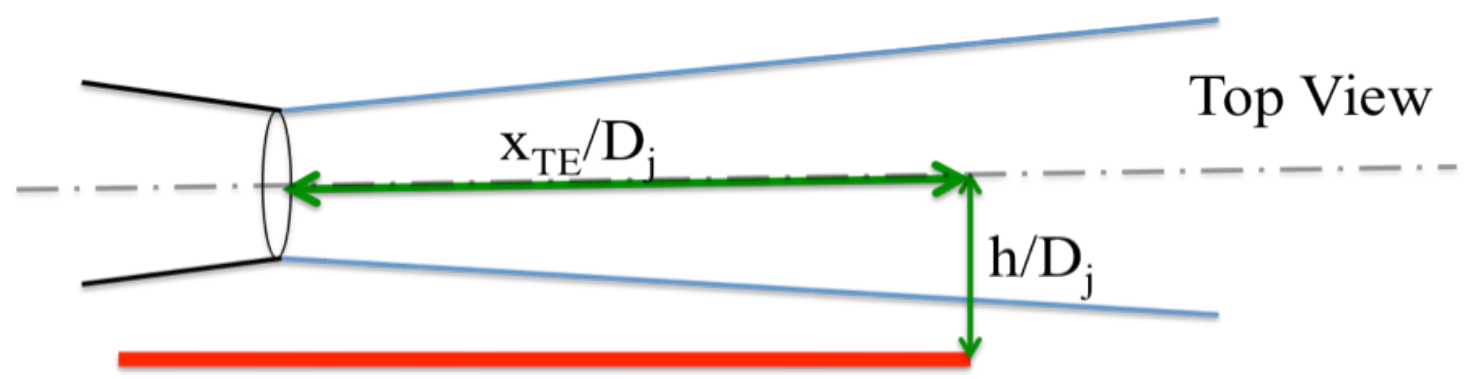

Figure 3: Schematic showing how the plate position nomenclature.

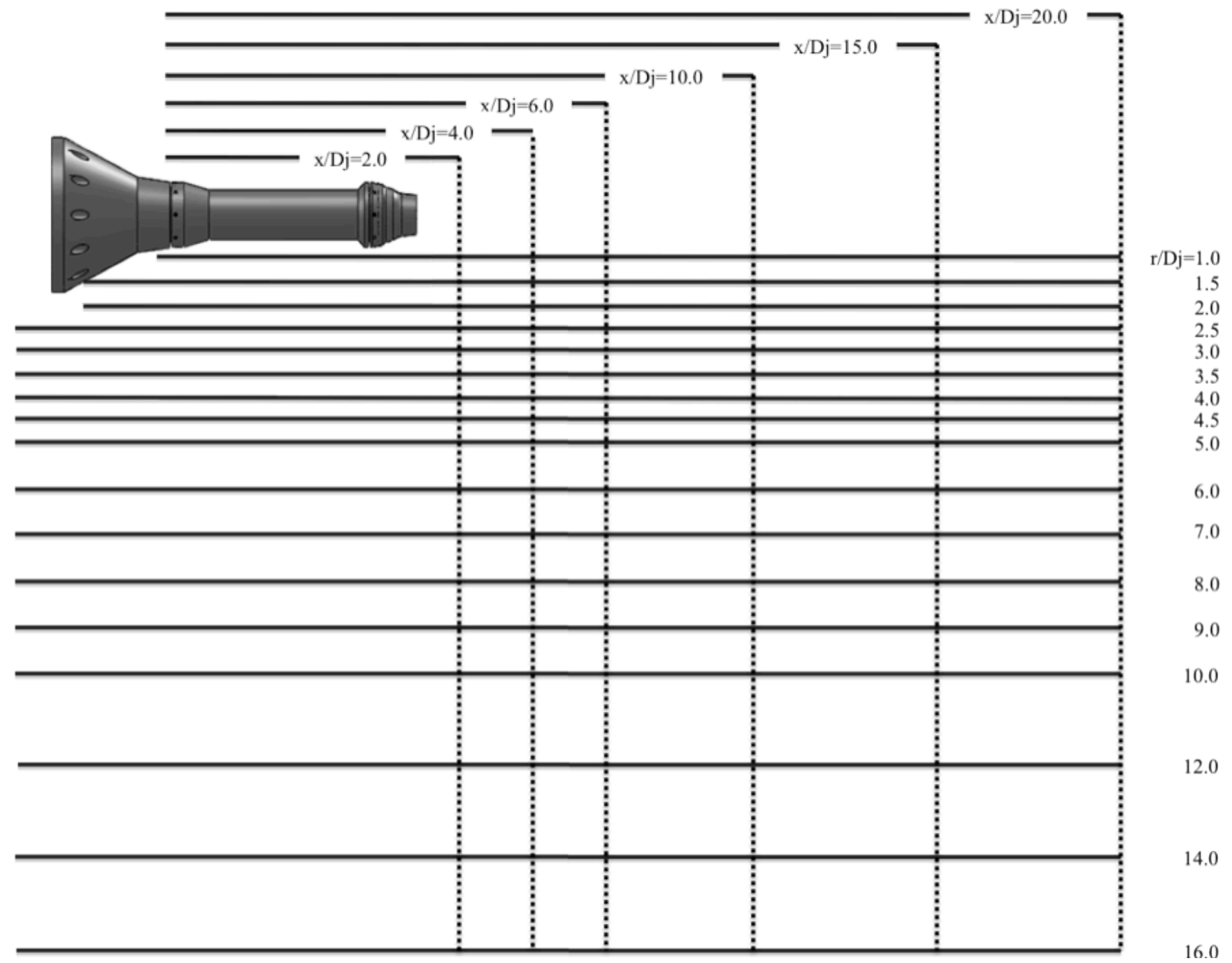

Figure 4: Drawing showing the surface locations tested. The surface lengths are shown above the jet and the radial locations are shown below the jet so that each intersection of a solid and dotted line represents the trailing edge location of one surface tested. Note that each surface location was repeated on both sides of the jet (as a shield and reflector of sound).

4

This work is declared a work of the U.S. Government and is not subject to copyright protection in the United States. Approved for public release; distribution is unlimited. 


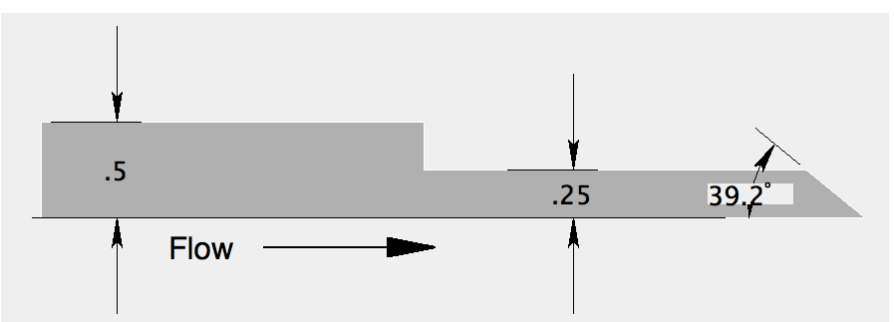

Figure 5: Schematic drawing of the surface trailing edge as viewed from the top.

The Jet-Surface Interaction Test included subsonic and supersonic jet exit conditions in several important flow regimes. The subsonic jet conditions (Table 1), acquired using a round convergent nozzle (SMC000, Figure 6), included a $\mathrm{M}_{\mathrm{a}}=0.5$ cold point to represent the dynamics in a low-speed jet and three jet conditions, ranging from unheated to a static temperature ratio of $\mathrm{T}_{\mathrm{s}} / \mathrm{T}_{\mathrm{a}}=2.70$, at $\mathrm{M}_{\mathrm{a}}=0.9$ to capture the affect of heat on the jet/surface interaction noise. The supersonic jet conditions (Table 2) were acquired using a convergentdivergent (C-D) nozzle (SMC016, Figure 7) with a design Mach number of $\mathrm{M}_{\mathrm{d}}=1.5$ (although experiments showed the shock free point to actually be closer to $\mathrm{M}_{\mathrm{d}}=1.48$ ). While all the supersonic jet conditions were unheated, the under-expanded, ideally expanded, and over-expanded flow regimes are all represented. Finally, one cold jet point was acquired using the convergent nozzle to represent the trans-sonic region (Table 1, setpoint 9010).

Ambient temperature, pressure, and humidity and all jet conditions (e.g. pressure, temperature, etc.) were recorded by the facility ESCORT computer system. As noted in Table 1 and Table 2, each jet exit condition, defined by a Mach number and a static temperature ratio $\left(\mathrm{T}_{\mathrm{s}} / \mathrm{T}_{\mathrm{a}}\right)$, was assigned a "setpoint" code and stored in the ESCORT computer. ESCORT then computed a real time error value (updated at $1 \mathrm{~Hz}$ ) using the setpoint and the current jet conditions to ensure the data acquired was at the desired jet exit conditions. The total error value, computed as an L2-norm using Mach number and static temperature ratio, must remain below $0.5 \%$ during the entire acquisition time for the data to be accepted.

Far-field noise data were acquired from an array of 24microphones located on an arc centered on the jet exit with a radius of 150". The $1 / 4$ " microphones (Bruel \& Kjaer type 4939) were placed at $5^{\circ}$ intervals covering from approximately $50^{\circ}$ upstream to $165^{\circ}$ downstream (see Figure 2). Bruel \& Kjaer Nexus units provided amplification and signal conditioning. Data were digitized at $200 \mathrm{kHz}$ sample rate $(90 \mathrm{kHz}$ low pass Nyquist filter) using a DataMAX Instrumentation Recorded from R.C. Electronics. Once acquired, the time series data were transformed into narrowband spectra (using a $2^{14}$ point Kaiser window for a frequency resolution of $12.21 \mathrm{~Hz}$ ) and background noise, measured each day before the test, was subtracted on a frequency by frequency basis. The data were then corrected to account for the frequency response of each microphone using the current calibration obtained from Bruel
\& Kjaer. Finally, the data were transformed to a lossless condition and scaled to an arbitrary distance of $100 \mathrm{D}_{\mathrm{j}}$ from the nozzle exit by correcting for the atmospheric attenuation and spherical spreading of sound.

When the axial and radial surface positions were combined with the different jet exit conditions, data were acquired for over 1600 different configurations during the test. There was a need, therefore, for a noise metric that efficiently shows where jet-surface interaction noise was created and where jet noise was shielded. Arc-Integrated Overall Sound Pressure Level (AI-OASPL) is a representation of the total sound pressure level passing an arc array of microphones. AI-OASPL is computed by integrating the spectra measured at each microphone across all frequencies to get the Overall Sound Pressure Level (OASPL). These OASPL values are then integrated across the arc length of the microphone array to give one number that represents the total sound level for a given configuration. Mathematically, if the radius of the microphone array arc is constant $(\mathrm{R})$, then the AI-OASPL can be written in term of polar angle $(\Theta)$ as:

$$
A I-O A S P L=\int_{\theta_{1}}^{\theta_{2}} \int_{f_{1}}^{f_{2}} R * S P L(f, \theta) d f d \theta
$$

where $\operatorname{SPL}(\mathrm{f}, \Theta)$ is the sound pressure level in Pascals. Note that AI-OASPL is sensitive to the radius of the microphone array because the metric does not fully account for the spherical spreading of the sound waves unlike the more common Overall Power Level (OAPWL). However, a proper OAPWL calculation of the jet-surface configurations would require data at many azimuthal angles to account for the asymmetry of the problem and these measurements were not available during this test entry.

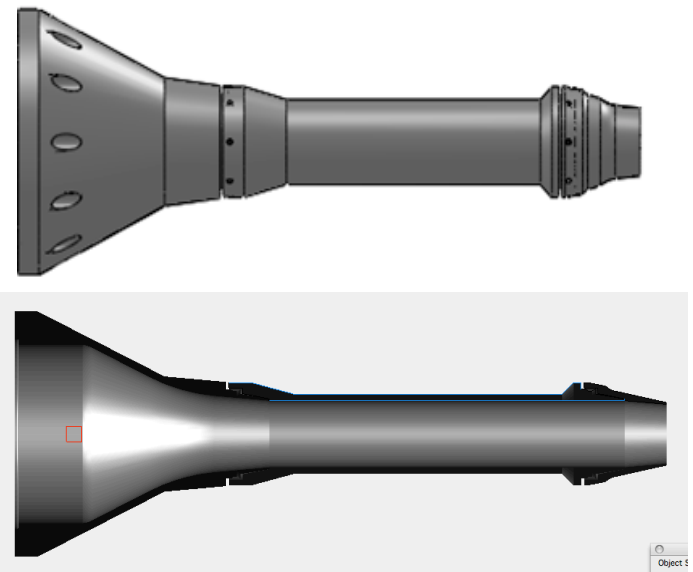

Figure 6: The round convergent nozzle (SMC000) exterior (top) and interior (bottom). Exit diameter is $D_{j}=2$ ". Note the 12" section of straight pipe between the initial contraction and the nozzle. 


\begin{tabular}{|c|c|c|c|c|}
\hline Setpoint & $\begin{array}{c}\mathrm{NPR} \\
\mathrm{P}_{\mathrm{j}} / \mathrm{P}_{\mathrm{a}}\end{array}$ & $\mathrm{T}_{\mathrm{s}} / \mathrm{T}_{\mathrm{a}}$ & $\begin{array}{c}\mathrm{M}_{\mathrm{a}} \\
\mathrm{V}_{\mathrm{j}} / \mathrm{c}_{\mathrm{a}}\end{array}$ & $\begin{array}{c}\text { Mass Flow } \\
(\mathrm{lbm} / \mathrm{s})\end{array}$ \\
\hline 3 & 1.197 & 0.950 & 0.5 & 0.87 \\
\hline 7 & 1.860 & 0.835 & 0.9 & 1.91 \\
\hline 27 & 1.360 & 1.746 & 0.9 & 0.86 \\
\hline 46 & 1.227 & 2.700 & 0.9 & 0.55 \\
\hline 9010 & 3.182 & 0.735 & 1.18 & 3.33 \\
\hline
\end{tabular}

Table 1: Jet exit conditions for the data acquired using the SMC000 round convergent nozzle $\left(D_{\mathrm{j}}=\mathbf{2 . 0}\right.$ ").

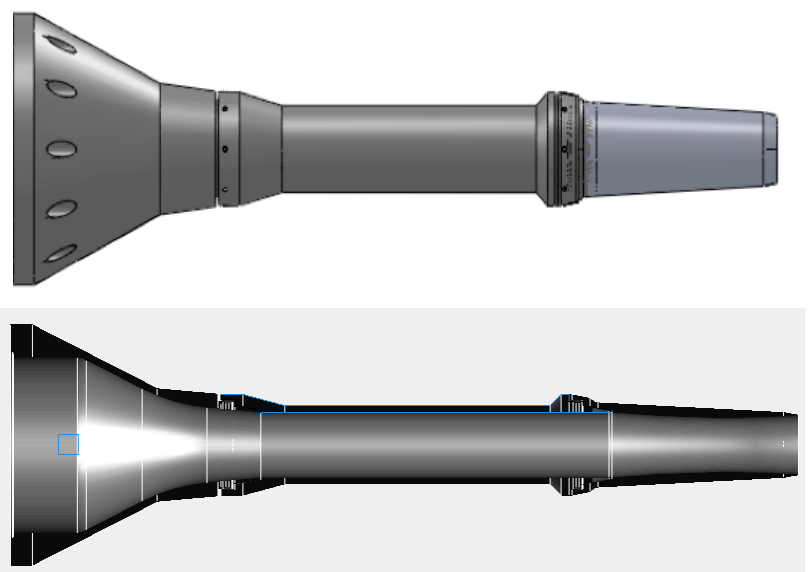

Figure 7: The round convergent-divergent nozzle (SMC016) exterior (top) and interior (bottom). The design Mach number is $M_{d}=1.5$ and the exit diameter is $D_{j}=2 "$.

\begin{tabular}{|c|c|c|c|c|}
\hline Setpoint & $\begin{array}{c}\mathrm{NPR} \\
\mathrm{P}_{\mathrm{i}} / \mathrm{P}_{\mathrm{a}}\end{array}$ & $\mathrm{T}_{\mathrm{j}} / \mathrm{T}_{\mathrm{a}}$ & $\begin{array}{c}\mathrm{M}_{\text {ideal }} \\
\mathrm{V}_{\mathrm{i}, \text { idea }} / \mathrm{c}_{\mathrm{i}}\end{array}$ & $\begin{array}{c}\text { Mass Flow } \\
(\mathrm{lbm} / \mathrm{s})\end{array}$ \\
\hline 11606 & 2.750 & 0.750 & 1.29 & 2.47 \\
\hline 11610 & 3.593 & 0.694 & 1.48 & 3.30 \\
\hline 11617 & 3.182 & 0.660 & 1.61 & 3.94 \\
\hline
\end{tabular}

Table 2: Jet exit conditions for the data acquired using the convergent-divergent (SMC016) round nozzle with a design Mach number of 1.5.results and analysis

\section{Unheated Subsonic Jets}

The Jet-Surface Interaction Test was designed to compile an experimental database for developing and validating noise prediction methods that include the effects of solid surfaces. It is, therefore, important for the dataset acquired during this phase to capture each of the different jet/surface interaction regions: surface as a noise source, surface as a noise shield, and surface as a reflector of noise. As a representative sample, Figure 8 shows spectra acquired at $60^{\circ}, 90^{\circ}$, and $150^{\circ}$ where the surface is between the jet and the microphone array at $\mathrm{x}_{\mathrm{TE}} / \mathrm{D}_{\mathrm{j}}=10$ and $\mathrm{h} / \mathrm{D}_{\mathrm{j}}$ varies from 1 to 10 . The jet is operating at setpoint 7. The spectra at $60^{\circ}$ and $90^{\circ}$ show a low frequency augmentation consistent with jet-surface interaction noise. This noise source reaches its peak amplitude around $90^{\circ}$, as expected for a dipole source, and decreases significantly as the surface moves out of the flow (increasing $h / D_{j}$ ). There is also a considerable amount of jet noise shielded by the surface at these angles, particularly at frequencies above the peak jet noise frequency. Phased array data has shown that high frequency jet noise originates near the nozzle exit where the turbulent length scales are smallest and where the surface provides the most shielding area. The shielding effect also increases at $60^{\circ}$ and $90^{\circ}$ as the surface moves away from the jet because the surface becomes effectively larger as it moves toward the microphones. However, the opposite is true at downstream angles $\left(150^{\circ}\right.$ in Figure 8$)$. More noise sources are exposed to the microphones when the surface moves away from the jet, minimizing the shielding effect in the direction of the peak jet noise. This exchange is clearly illustrated in the OASPL directivity (Figure 8) where the downstream angles all have similar values independent of the surface position (or presence of the surface). These directivity data also show that the surface decreases the noise measured on a frequencyintegrated basis at every surface position except the closest one $\left(\mathrm{h} / \mathrm{D}_{\mathrm{j}}=1\right)$. In this way a surface near a jet may be an advantage.

The data presented in Figure 8 show many details about the noise produced or shielded for five surface positions and one jet condition. However, consider that data were acquired for over 1600 configurations during the Jet-Surface Interaction Test and the need for a more efficient way to evaluate the data becomes apparent. The Arc-Integrated Overall Sound Pressure Level (AI-OASPL), introduced in the data processing section above, reduces the data from each configuration to a single number by integrating across spectral frequency and polar angle. The net change in total sound level is calculated by subtraction the AIOASPL of the isolated jet from the AI-OASPL calculated for the jet-surface configuration. This metric gives an overview of how the surface affects the noise levels but it should be noted that many details are lost in this calculation. For example, it is possible that the jet-surface interaction noise created for a given surface position is cancelled by the noise shielded when the integration is computed. In this case the AI-OASPL will show no change to the sound levels when, in fact, there are differences. The $\triangle \mathrm{AI}-\mathrm{OASPL}$ is still a useful metric and can be used to identify regions of interest and find general trends in a large dataset.

The $\triangle$ AI-OASPL values for the jet operating at setpoint 7 and the surface positioned between the jet and the microphone array are shown in Figure 9. The jet-surface interaction noise at this operating condition peaks for surfaces at $\mathrm{x}_{\mathrm{TE}} / \mathrm{D}_{\mathrm{j}}>6$ and $\mathrm{h} / \mathrm{D}_{\mathrm{j}}<2$ where the surface is subject to the greatest area of high speed flow. The noise shielding effect is greatest for the largest surfaces $\left(\mathrm{x}_{\mathrm{TE}} / \mathrm{D}_{\mathrm{j}}>15\right)$ and decreases slightly as $\mathrm{h} / \mathrm{D}_{\mathrm{j}}$ increases, exposing more sources to the downstream microphones. A reference line representing a $7^{\circ}$ jet spreading angle, commonly used as a guideline in isolated jets, has also been included in Figure 9. While the $7^{\circ}$ spreading angle may not be accurate when the surface is present, it appears to divide the regions where the surface increases the total noise from the regions where the surface shielding effect reduces the overall noise. Or as a general design guideline, these data indicate that a surface placed outside a $7^{\circ}$ cone will not increase the noise but may reduce it via shielding at this jet operating condition.

6

This work is declared a work of the U.S. Government and is not subject to copyright protection in the United States. Approved for public release; distribution is unlimited. 

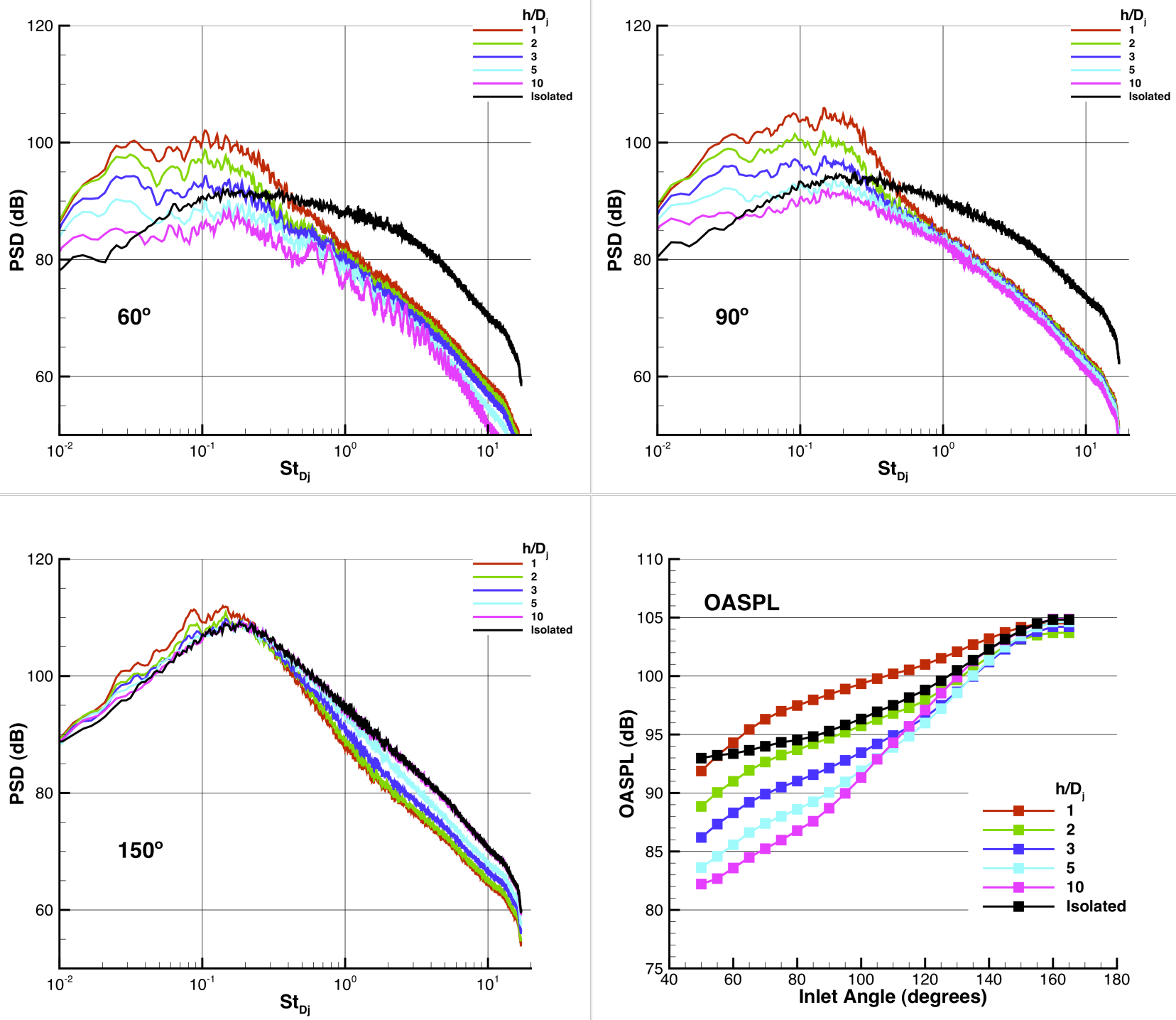

Figure 8: Spectra and directivity from a jet operating at setpoint 7 with a surface length $0 f x / D_{j}=10$ placed at radial locations ranging from $h / D_{j}=1$ to $h / D_{j}=10$ compared to an isolated (no surface) jet. Data are corrected for atmospheric attenuation and scaled to an arc centered on the jet exit with a radius of $1^{100 D_{j}}$

The two sources of jet-surface noise are the surface loading, or 'scrubbing', source and the trailing edge source. In practice, these sources may be difficult separate because both are created by the same turbulent flow making them spectrally and spatially similar. One method of separating the contributions of each source is to compare the noise on the shielded side with the noise on the reflected side of the surface. In this analysis, it is assumed that directivity of the trailing edge noise source has a cardioid shape [??] and is, therefore, the same on both sides of the surface. Then if the scrubbing noise is blocked by the surface on the shielded side, only the trailing edge noise reaches the observer. Conversely, both the scrubbing noise and trailing edge noise are observed on the reflected side of the surface. An example of this analysis using data acquired with a surface at $\mathrm{x}_{\mathrm{TE}} / \mathrm{D}_{\mathrm{j}}=15$ and $\mathrm{h} / \mathrm{D}_{\mathrm{j}}=1.5$ is shown in Figure 10. In this case, the low frequency augmentation associated with the jetsurface interaction noise is very similar on sides of the surface indicating that the trailing edge noise is the dominant source below Strouhal frequencies of 0.2 in this configuration. This conclusion is supported by phased array data which shows low frequency noise source located at the trailing edge of the surface for all configurations where the jet flow impinged on

7

This work is declared a work of the U.S. Government and is not subject to copyright protection in the United States. Approved for public release; distribution is unlimited. 
the surface [12]. At higher frequencies, a combination of scrubbing noise and reflected jet noise appears when the surface is in the reflected position.

Perfect reflection of a simple point source increases the sound levels by $6 \mathrm{~dB}$. Jet noise, however, is not a simple point source but rather a spatial distribution of incoherent sources. In this case, reflection only adds $3 \mathrm{~dB}$ to the sound level. In Figure 10 , the sound level measured on the reflected side of the surface is approximately $3 \mathrm{~dB}$ above the isolated jet at Strouhal frequencies above 2.5. This increase is likely due to jet noise reflecting off the surface. Between $\mathrm{St}_{\mathrm{Dj}}=0.2$, where the surface begins to shield the scrubbing noise, and $\mathrm{St}_{\mathrm{Dj}}=2.5$, the increase in sound level measured on the reflected side of the surface is likely a combination of jet noise reflection and jet scrubbing noise.

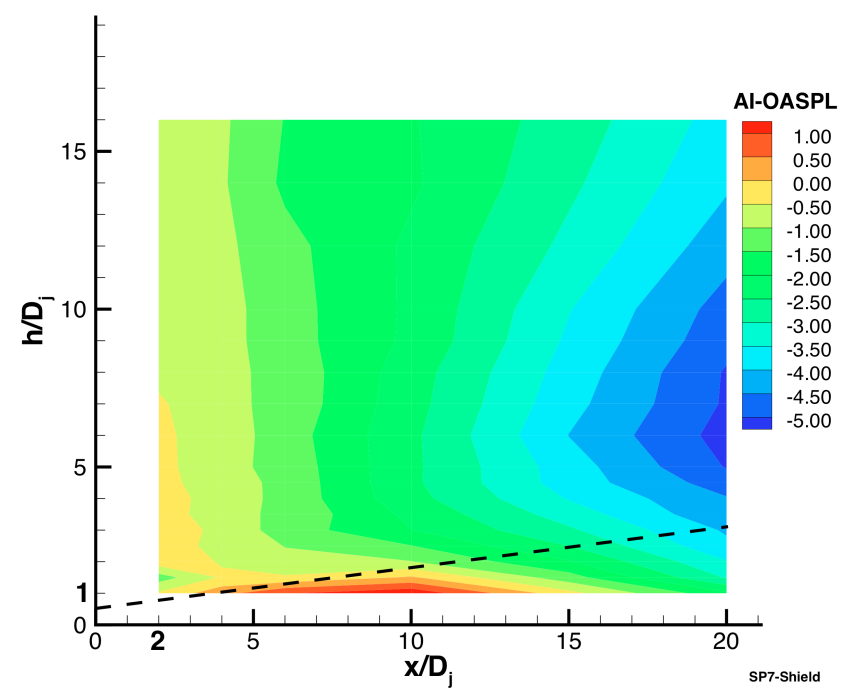

Figure 9: AI-OASPL for the jet operating at setpoint 7 and the surface in the shielded configuration as a function of surface trailing edge and radial location relative to the isolated jet. The black dashed line represents a $7^{\circ}$ jet spreading angle from the nozzle lip.

The spectral plots, OASPL directivity, and AI-OASPL maps show how the noise changes when a surface in placed near a jet with a given velocity but do not show how the jetsurface interaction noise changes when the jet velocity changes. Figure 11 shows how the jet-surface interaction noise scales as the jet velocity increases. The jet-surface interaction noise was extracted from the spectra at $90^{\circ}$ by computing the OASPL over the frequencies where the interaction noise exceeds the isolated (no surface) jet for the shielded observer. The contribution of the jet mixing noise was then removed by subtracting the OASPL of the isolated jet computed over the same frequency range. The result is plotted as a function of jet velocity and compared to lines of constant velocity scaling. The results, taken at $h / D_{j}=1$, show that the velocity scaling falls from $\mathrm{U}_{\mathrm{j}}^{8}$, consistent with Lighthill's analogy for jet mixing noise, to a value between $U_{j}^{5}$, predicted for a perfectly rigid plate [3], and $U_{j}^{6}$, predicted for a cases of high fluid loading on the surface [2]. The shortest surface, $x_{\mathrm{TE}} / \mathrm{D}_{\mathrm{j}}=4$, has a velocity scaling close to $U_{j}^{5}$ while the longer surfaces all scale close to $U_{j}^{5.5}$. The experiments of Head and Fisher [9] and Lawrence et. al. [1] both found a scaling of $\mathrm{U}_{\mathrm{j}}^{6}$ for longer surfaces. However, Lawrence et. al. also showed that there is a transition region where the scaling goes from $U_{j}^{5}$ to $U_{j}^{6}$ as the surface extends downstream [1]. Furthermore, Crighton and Leppington showed theoretically that the scaling changes as the rigidity of plate changes [4], and, therefore, it is possible that the change in velocity scaling is caused by a loss of rigidity as the surfaces become larger and are subjected to more flow in the experiments ${ }^{1}$. Unfortunately, a measure of the surface rigidity was not recoded during these tests but should be considered in future work.

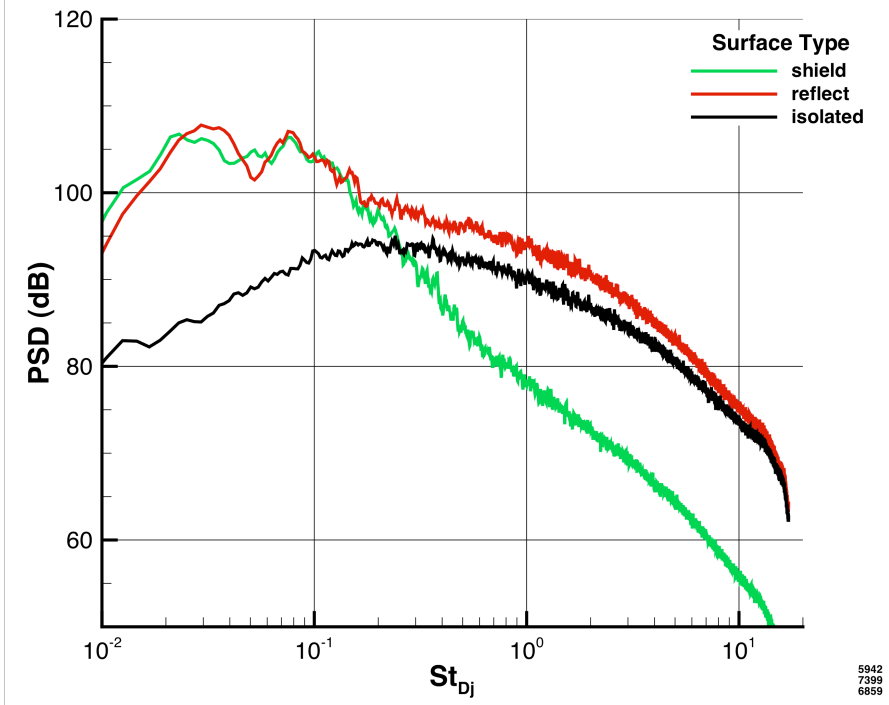

Figure 10: Spectra measured at $90^{\circ}$ and scaled to $100 D_{j}$ from the shielded (green) and reflected (red) side of the surface for a jet operating at setpoint 7 with the surface at $\mathrm{x}_{\mathrm{TE}} / \mathrm{D}_{\mathrm{j}}=15$ and $\mathrm{h} / \mathrm{D}_{\mathrm{j}}=1.5$ compared to the isolated jet (black).

This work is declared a work of the U.S. Government and is not subject to copyright protection in the United States. Approved for public release; distribution is unlimited.

\footnotetext{
${ }^{1}$ The $1 / 2$ " aluminum plate used to form the surface in these tests was not expected to deform under the force of the jet flow. However, the mounting structure may not have been perfectly rigid for the larger surfaces. 8
} 


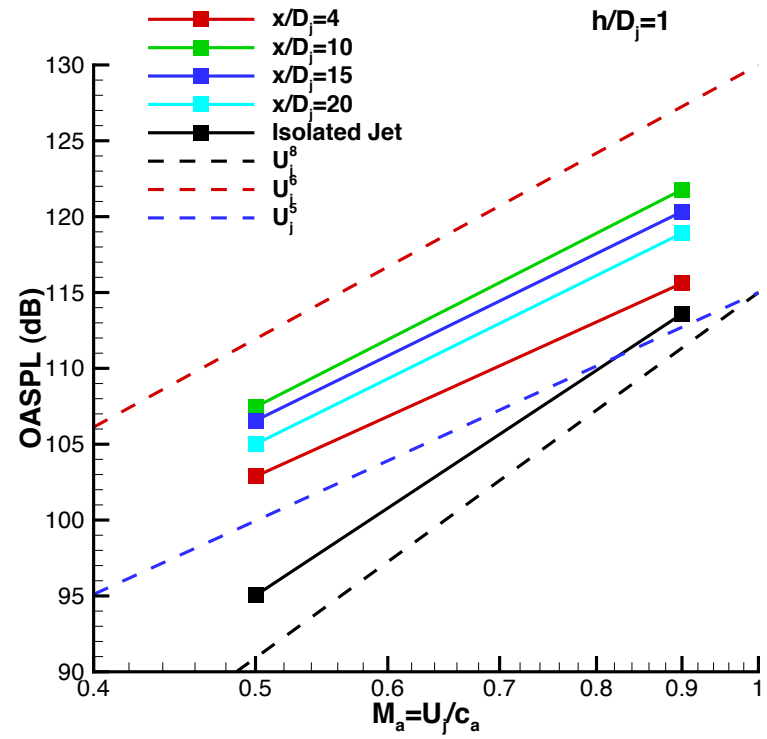

Figure 11: Jet-surface noise scaling with velocity for 4 different surface lengths at $h / D_{j}=1$ measured at the $90^{\circ}$ microphone location. Reference lines show $\mathbf{U}_{j}^{8}$ (black dashed), $U_{j}^{6}$ (red dashed), and $U_{j}^{5}$ (blue dashed) scaling.

\section{Hot Subsonic Jets}

Many real-world jets are heated and, therefore, the effect of a surface near a hot jet was also considered during the JetSurface Interaction Test. Two heated jet conditions, setpoints 27 and 46 in Table 1, were selected for the test. These points have the same acoustic Mach number, $\mathrm{M}_{\mathrm{a}}=0.9$, but different static temperature ratios (1.746 and 2.70 for setpoint 27 and 46 respectively). When combined with setpoint $7 \quad\left(\mathrm{M}_{\mathrm{a}}=0.9\right.$, unheated), these three jet conditions should allow the jet temperature effects to be separated from changes in velocity.

A comparison of the spectra acquired at setpoints 7, 27, and 46 with a surface at $\mathrm{x}_{\mathrm{TE}} / \mathrm{D}_{\mathrm{j}}=10$ and $\mathrm{h} / \mathrm{D}_{\mathrm{j}}=1$ is shown in Figure 12. These data, measured at $90^{\circ}$ relative to the jet axis, show that the hot jets are very similar to the unheated jet up to $\mathrm{St}_{\mathrm{Dj}} \approx 0.1$. Above this frequency, however, the spectra measured for the heated jets decays on a slope that parallels the cold jet but at a lower frequency. Two possible explanations for this behavior at a given surface location are that (1) the jet-surface interaction source is weaker when the jet is hot and (2) the surface provides more shielding of the heated jet than the cold jet. In fact, these explanations may both be partially correct and due to the same underlying cause. Particle Image Velocimetry data acquired using the same SMC000 nozzle on the SHJAR at these setpoints show that the potential core shortens from approximately $\mathrm{x} / \mathrm{D}_{\mathrm{j}}=8$ for the cold jet to $\mathrm{x} / \mathrm{D}_{\mathrm{j}}=6$ at setpoint 27 and $x / D_{j}=5$ at setpoint 46 [21]. Thus, the flow velocity at the trailing edge of the surface would be lower as the jet temperature increases reducing the noise produced. At the same time, more of the jet noise sources would be shielded from the observer. The AI-OASPL data calculated as a function of surface position for setpoint 27 (Figure 13) and setpoint 46
(Figure 14) supports this hypothesis. Compared to the AIOASPL data for the unheated $\mathrm{M}_{\mathrm{a}}=0.9$ jet (Figure 9), the maximum AI-OASPL above the isolated jet occurs at surface trailing edge locations farther upstream in the heated jets. Additionally, the maximum AI-OASPL value decreases at the jet temperature increases.

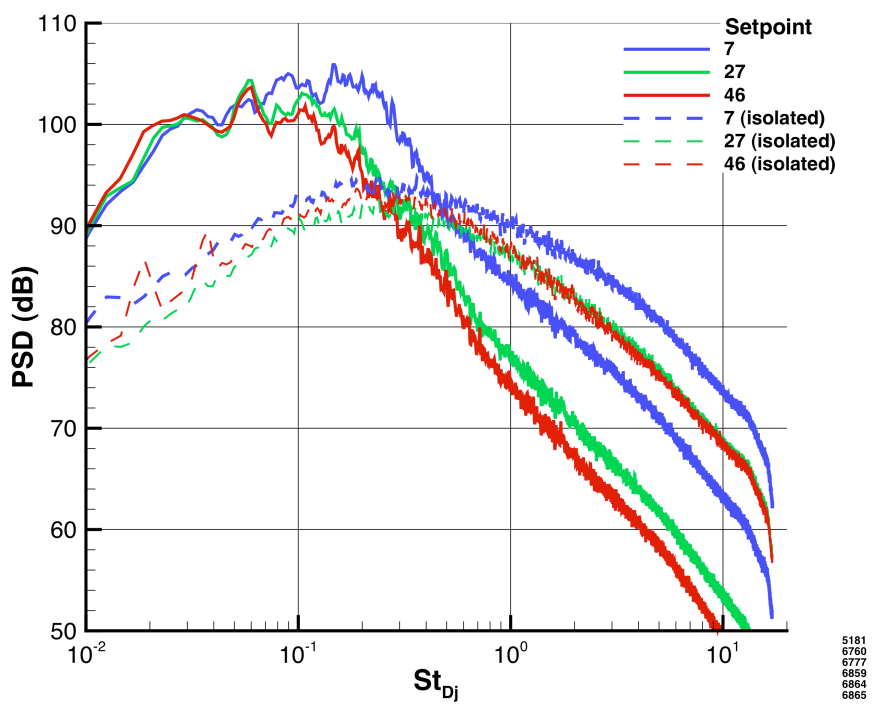

Figure 12: Effect of heating the jet flow on the jet-surface interaction noise and on the noise shielding effect. The solid lines show the noise at each setpoint with the surface trailing edge at $x_{\mathrm{TE}} / \mathrm{D}_{\mathrm{j}}=10$ and $h / \mathrm{D}_{\mathrm{j}}=1$ in the shielded configuration as measured at $90^{\circ}$. The dashed line represent the corresponding isolated jet noise also measured at $90^{\circ}$. Data have been corrected for atmospheric attenuation and scaled to $R=100 D_{j}$ arc.

Data acquired from a cold jet and two heated jets all with the same acoustic Mach number $\left(\mathrm{M}_{\mathrm{a}}\right)$ shows that the surface location that produces the largest jet-surface interaction noise moves upstream as the jet temperature increases. Velocity data from these jets also shows that the potential core becomes shorter as the temperature increases. Analysis by Bridges shows that the jet potential core length for these jets may be normalized by the Witze correlation parameter [21]. The Witze parameter [22], which is 7.79 at setpoint 7, 5.98 at setpoint 27, and 4.98 at setpoint 46 , represents the potential core length for each jet [21]. Figure 15 shows the $\triangle$ AI-OASPL maps in the region of peak jet-surface interaction noise at setpoints 7, 27, and 46 where the surface trailing edge location has been normalized by the jet diameter and the Witze parameter $\left(\mathrm{x}_{\mathrm{w}}\right)$. The Witze normalization improves the alignment of the trailing edge location where the peak jet-surface interaction noise is produced but does not fully account for the change in source location observed in the heated jets. It also does not explain the measurably smaller peak $\triangle$ AI-OASPL at setpoint 46 indicating that another mechanism is affecting the jet-surface noise. That mechanism may also be found in the velocity data acquired at

9

This work is declared a work of the U.S. Government and is not subject to copyright protection in the United States. Approved for public release; distribution is unlimited. 
these jet conditions. These data showed that jet spreading angle, based on the half-velocity width, narrows as the jet temperature increases. As a result, a surface located at $h / D_{j}=1$ would be subject to a lower mean velocity flow at setpoint 46 than at setpoint 7 with a corresponding reduction in the jet-surface noise. Unfortunately the coarse nature of this data set and the $\mathrm{h} / \mathrm{Dj}=1$ limit on radial position make it very difficult to fully evaluate this effect but it should be a focus of future investigation.

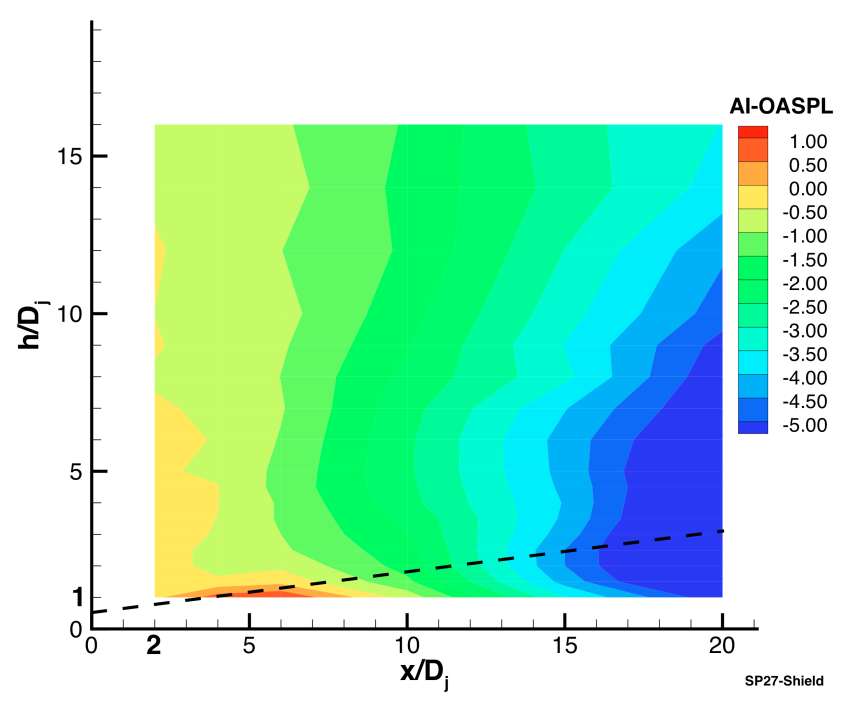

Figure 13: AI-OASPL, relative to the corresponding isolated jet, as a function of surface trailing edge and radial location measured at setpoint 27 relative to an isolated jet. The surface is in the shielded configuration so this data may be compared to Figure 9 (setpoint 7) and Figure 14 (setpoint 46). The $7^{\circ}$ jet spreading line is also included here as a spatial reference.

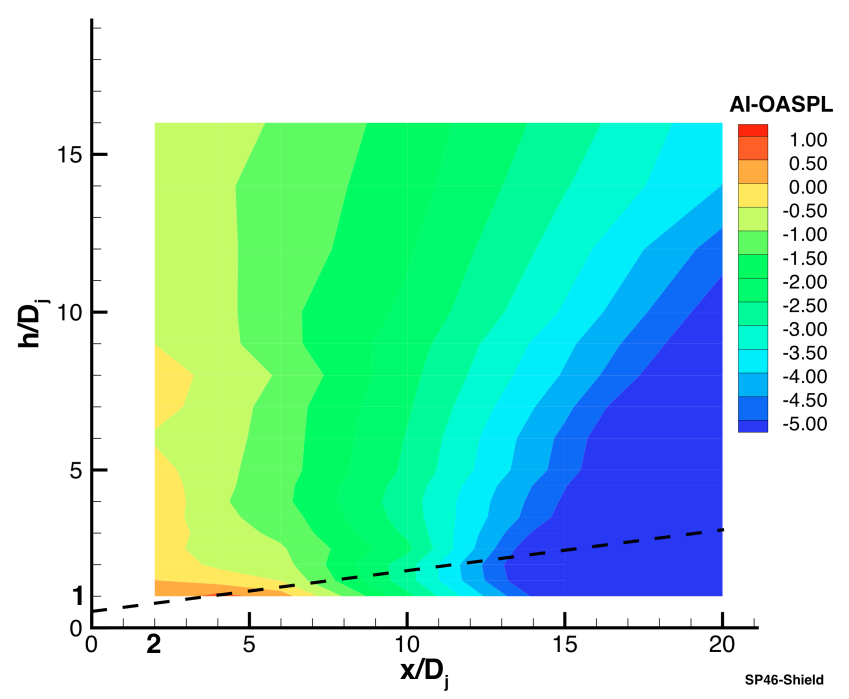

Figure 14: AI-OASPL, relative to a corresponding isolated jet, as a function of surface trailing edge and radial location measured at setpoint 46 relative to an isolated jet. The surface is in the shield configuration so this data may be compared to Figure 9 (setpoint 7) and Figure 13 (setpoint 27). The $7^{\circ}$ jet spreading line is also included here as a spatial reference.

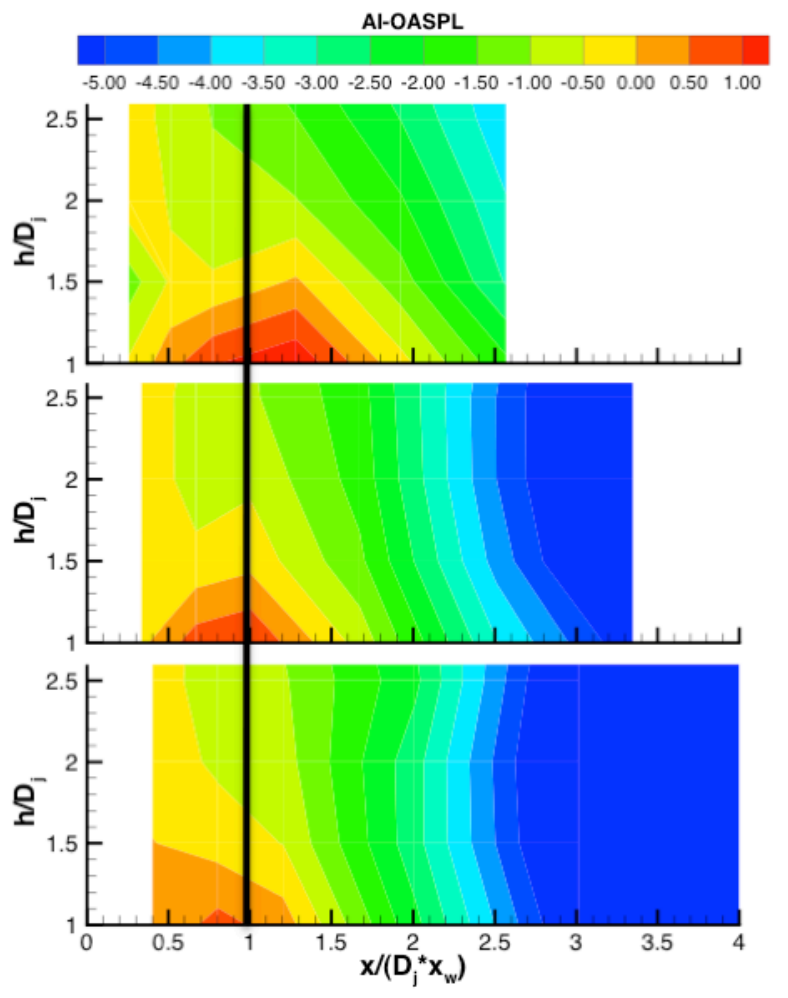

Figure 15: AI-OASPL relative to the corresponding isolated jet, in the peak jet/surface interaction noise region at setpoints 7 (top), 27 (middle), and 46 (bottom) where the surface trailing edge location $\left(x_{\mathrm{TE}}\right)$ has been normalized by the Witze parameter $\left(x_{w}\right)$. As a reference, a vertical line has been drawn at $x /\left(D_{j} * x_{w}\right)$.

\section{Supersonic Jets}

Theories and experimental data have shown that jet-surface interaction noise increases as jet velocity to the fifth $\left(\mathrm{U}_{\mathrm{j}}^{5}\right)$ or sixth power $\left(\mathrm{U}_{\mathrm{j}}^{6}\right)$ depending on factors such as surface stiffness (see Figure 11). However, it is also known that jet mixing noise increases as jet velocity to the eighth power $\left(\mathrm{U}_{\mathrm{j}}^{8}\right)$. As a result, the jet-surface noise is an important contributor to the total noise at lower jet Mach numbers but becomes less so as the jet velocity increases and the jet mixing noise is dominant. At this higher jet exit velocities, the surface will continue to shield or reflect the jet mixing noise. In supersonic jets that are not ideally expanded, the surface may also alter the shock structure and, thereby, the broadband shock noise directly.

Data were acquired during the Jet/Surface Interaction Test to represent each of the three supersonic flow regimes: underexpanded, ideally expanded, and overexpanded. A convergent-divergent (C-D) nozzle with an ideally expanded design Mach number, $\mathrm{M}_{\mathrm{d}}=1.5$ was used for these jet conditions (Table 2). When the jet is ideally expanded (setpoint 11610, 10

This work is declared a work of the U.S. Government and is not subject to copyright protection in the United States. Approved for public release; distribution is unlimited. 
Figure 16) the results follow the same general trend observed in the subsonic jets; jet-surface interaction noise is produced at low frequencies and the surface shields some of the high frequency noise sources (compare Figure 8 to Figure 16). However, that the jet-surface interaction noise is less significant to the overall noise level in the supersonic jet even though it has a higher absolute amplitude. The peak jet-surface interaction noise at $h / D_{j}=1$ is approximately $12 \mathrm{~dB}$ above the isolated jet noise at $\mathrm{M}_{\mathrm{a}}=0.9$ (setpoint 7) but only $5 \mathrm{~dB}$ above the isolated jet noise at $\mathrm{M}_{\mathrm{id}}=1.5$ (setpoint 11610). The AI-OASPL data at setpoint 11610 (Figure 17) shows that the shielding effect of the surface cancels or exceeds increased jet-surface noise at every surface position tested. In contrast, there was a relationship between surface position and increases or decreases in the AI-OASPL shown at $\mathrm{M}_{\mathrm{a}}=0.9$ (setpoint 7, Figure 9). The reduced importance of the jet-surface interaction noise at these higher Mach numbers occurs because the jet mixing noise increases as $\mathrm{U}_{\mathrm{j}}^{8}$ while the jet-surface interaction noise increase as approximately $\mathrm{U}_{\mathrm{j}}^{5.5}$.

Another difference between the subsonic and supersonic spectra appears in the $90^{\circ}$ measurement where there is a small bump in the spectra around $\mathrm{St}_{\mathrm{Dj}}=1$ when the surface is present (Figure 16). The frequency and spectral shape of this hump could be characteristic of broadband shock noise (BBSN). The C-D nozzle was designed to be shock free at this Mach number but it is very difficult to achieve a truly shock free flow in reality. One possible explanation is that the surface either creates or augments a shock structure in the jet. This hypothesis relies on the observation that the spectral hump is not present in the isolated jet. However, it persists at $h / D_{j}=10$ where the surface is unlikely to affect the jet flow. A more likely explanation is that the surface is shielding some of the jet mixing noise sources but not the BBSN. This hypothesis, which relies on the distribution of noise sources within the jet, cannot be confirmed with dataset but should be an area of interest in future testing.

The jet-surface interaction noise and shielding effect of the surface become significantly more complicated when a supersonic jet is operated at an overexpanded or underexpanded condition. At these operation conditions, broadband shock noise (BBSN) becomes an important noise source. BBSN is created by interactions between the turbulence in the mixing shear layer and the shock cells in the jet plume. The strength, spacing, and location of the shock cells are governed by the nozzle pressure ratio and dictate the frequency content and amplitude of the BBSN. The shock cells typically move downstream as the jet transitions from an overexpanded to an underexpanded condition. In a jet-surface configuration, the surface has the potential to alter the shock cell structure and, therefore, the BBSN. Figure 18 shows spectra measured at $60^{\circ}$, near the BBSN peak, for the overexpanded jet (setpoint 11606) when the surface trailing edge is at $\mathrm{x}_{\mathrm{TE}} / \mathrm{D}_{\mathrm{j}}=10$. At this operating condition, much of the BBSN appears to be shielded from the observer. In contrast, the surface does not shield much of the BBSN until it has reached $h / D_{j}=10$ (and is effectively much larger to the upstream microhpones) at the underexpanded operating condition (setpoint 11617, Figure 19). This result is consistent with the BBSN source (shock cells) moving downstream as the jet transitions from the overexpanded regime to the underexpanded regime. However, it is impossible to conclude that this is the only effect at work without knowing how the surface impacts the shock cell structure. Unfortunately, that data has not yet been acquired. Nevertheless, the significant reduction in BBSN measured in the overexpanded operating regime may offer a noise reduction opportunity for designers.
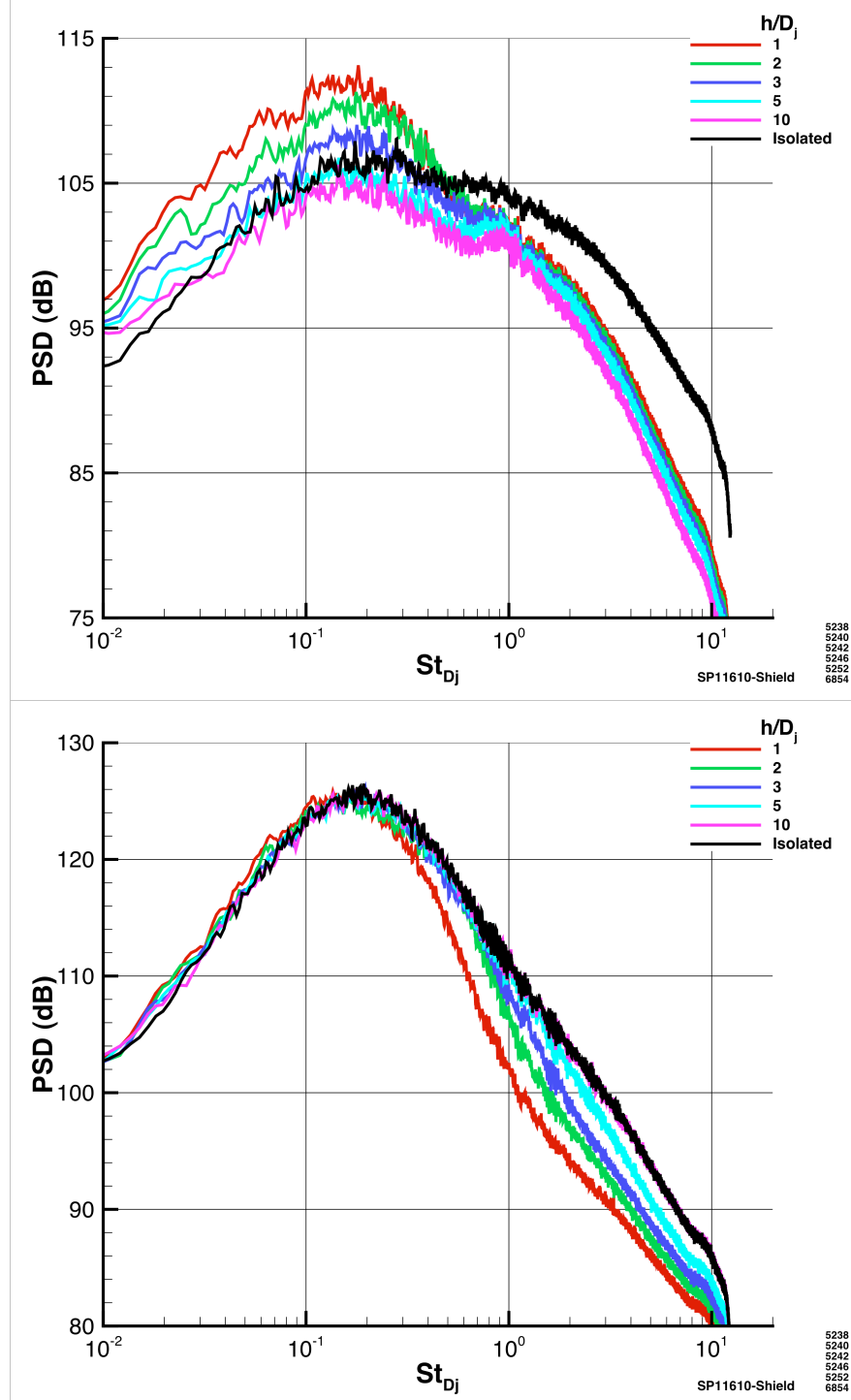

Figure 16: Spectra measured at $90^{\circ}$ and $150^{\circ}$, corrected for atmospheric attenuation and scaled to $R=100 D_{j}$, from an ideally expanded Mach 1.5 jet with a flat surface at $\mathbf{x}_{\mathrm{TE}} / \mathbf{D}_{\mathrm{j}}=\mathbf{1 0}$ in the noise shield configuration.

This work is declared a work of the U.S. Government and is not subject to copyright protection in the United States. Approved for public release; distribution is unlimited. 


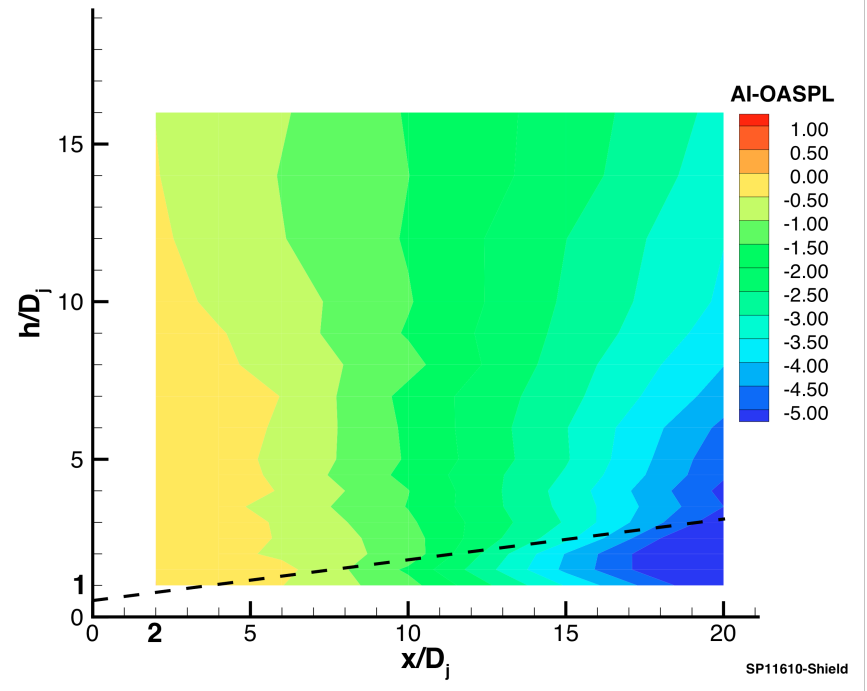

Figure 17: AI-OASPL a function of surface position for an ideally expanded Mach 1.5 unheated jet relative to the corresponding isolated jet. The black dashed line represents a $7^{\circ}$ jet spreading angle from the nozzle lip.

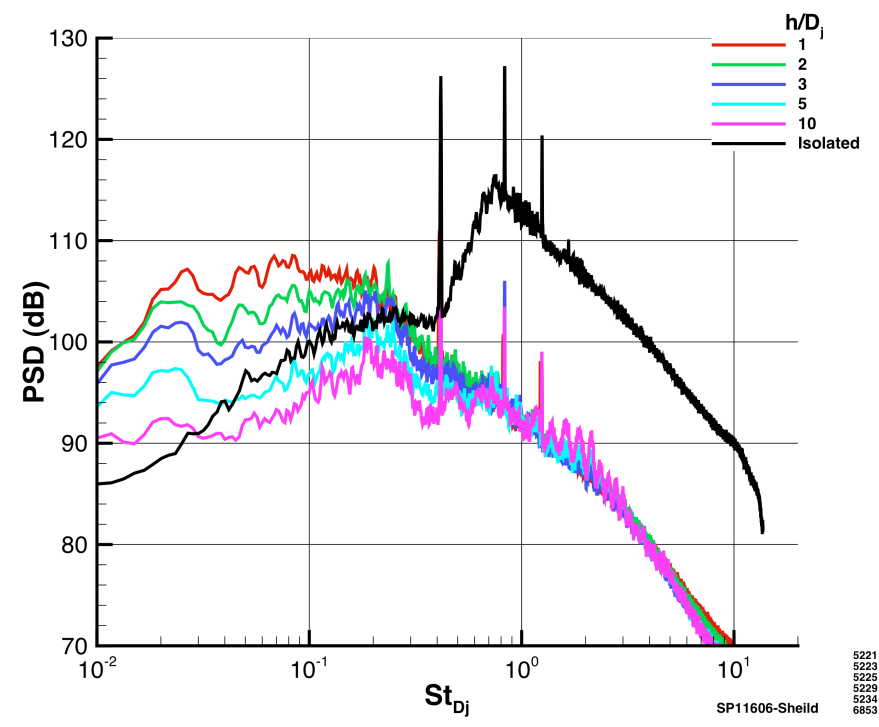

Figure 18: Spectra at $R=100 D_{j}$ and $60^{\circ}$ relative to the jet axis when the surface is at $x_{\mathrm{TE}} / \mathrm{D}_{\mathrm{j}}=10$ and the jet is overexpanded (setpoint 11606).

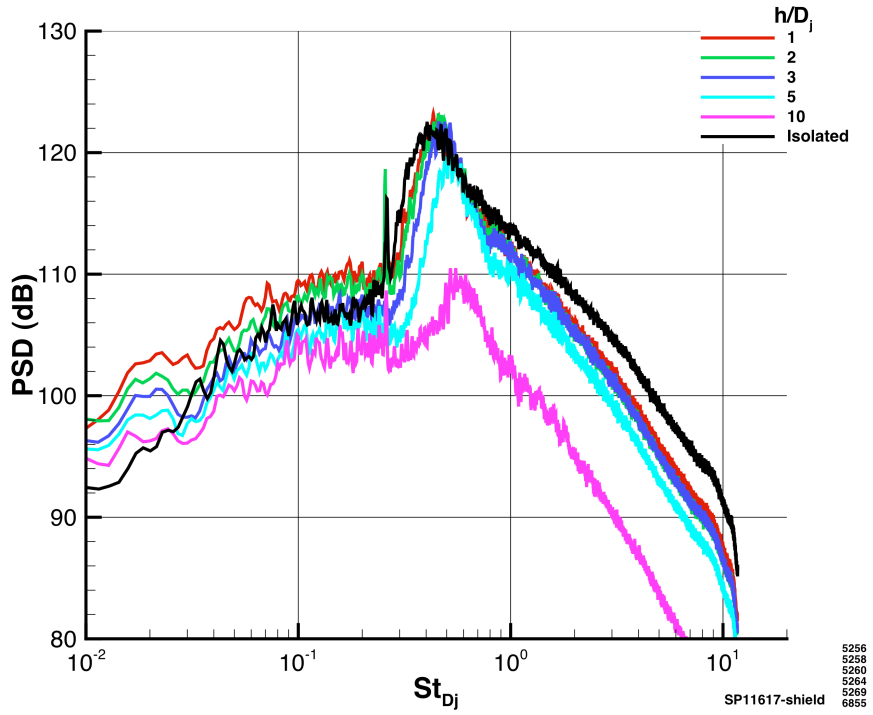

Figure 19: Spectra at $R=100 D_{j}$ and $60^{\circ}$ relative to the jet axis when the surface is at $x_{T E} / D_{j}=10$ and the jet is underexpanded (setpoint 11617).

\section{CONCLUSIONS}

The Jet-Surface Interaction Test program was envisioned to supply experimental data covering a wide range of simple surface geometries and jet flows for improving the current generation of aircraft noise prediction tools. The first part of the program, presented here, used a flat with a sharp trailing edge to study regions where the surface acts to shield the jet noise, where the surface acts to reflect the jet noise, and where the interaction between the jet and the surface produce additional noise. The test included a wide range of subsonic and supersonic jet conditions to increase the applicability of the data set. In all, nearly 1600 unique combinations of surface position and jet condition were tested. A subset of this dataset has been presented to show important features of the jet-surface interaction noise as jet velocity, jet temperature, and surface position change.

A theoretical framework for understanding jet/surface interaction noise has been developed by researchers dating back to the mid-1950's. This work has resulted in some general scaling rules for jet/surface noise. The data acquired during phase one of the Jet/Surface Interaction Test generally support these scaling rules. This data also offers some insight into how jet/surface noise predictions method might be developed or expanded. Normalizing the surface length using the Witze correlation parameter, for example, may be used to adjust the jet-surface interaction source region in hot jets. Insights like these coupled with the data for validation that will allow researchers to develop jet noise prediction methods that include the impact of nearby surfaces.

This work is declared a work of the U.S. Government and is not subject to copyright protection in the United States. Approved for public release; distribution is unlimited. 


\section{ACKNOWLEDGMENTS}

This work was supported by the NASA Fundamental Aeronautics Program, Sub-Sonic Project. Special thanks to James Bridges for reviewing the work and to the staff at the AAPL for their work on this project.

\section{REFERENCES}

[1] Lawrence, J.L.T, Azarpeyvand, M., and Self, R.H., "Interaction between a Flat Plate and a Circular Subsonic Jet", AIAA 2011-2745, 2011.

[2] Curle, N., "The influence of solid boundaries upon aerodynamic sound", Proc. Roy. Soc. of London, 231A, pp. 505-514, 1955.

[3] Ffowcs, J.E. and Hall, L.H., "Aerodynamic sound generation by turbulent flow in the vicinity of a scattering half plane", J. Fluid Mech., vol. 40(4), pp. 657-670, 1970.

[4] Crighton, D.G. and Leppington, F.G., "Scattering of aerodynamic noise by a semi-infinite compliant plate", J. Fluid Mech. Vol. 43(4), pp. 721-736, 1970.

[5] Chase, David M., "Sound radiated by turbulent flow off a rigid half-plane as obtained from a wavenumber spectrum of hydro-dynamic pressure", J. of the Acoustical Society of America vol. 52, pp. 1011-1022, 1972.

[6] Amiet, R.K., "Noise Due To Turbulent Flow Past a Trailing Edge", J. of Sound and Vibration vol. 47(3), pp. 387-393, 1976. [7] Singer, Bart A., Brentner, Kenneth S., Lockard, David P., and Lilley, Geoffrey M., "Simulation of Acoustic Scattering from a Trailing Edge”, AIAA 1999-0231, 1999.

[8] Casper, J. and Farassat, F., "Broadband Noise Predictions Based on a New Aeroacoustic Formulation", AIAA 2002-0802, 2002.

[9] Papamoschou, D., "Prediction of Jet Noise Shielding", AIAA 2010-653, 2010.

[10] Chase, David M., "Noise Radiated from an Edge in Turbulent Flow", AIAA J. vol. 13(8), pp. 1041-1047, 1075.

[11] Head, R.W. and Fisher, M.J., "Jet/Surface Interaction Noise: Analysis Of Farfield Low Frequency Augmentation of Jet Noise Due To The Presence Of A Solid Shield", AIAA 1976-502, 1976.

[12] Brooks, T.F. and Hodgson, T.H., "Trailing edge noise prediction from measured surface pressures", J. of Sound and Vibration, vol. 78, pp. 69-117, 1981.

[13] Howe, M.S., "Aerodynamic Noise of a Serreted Trailing Edge", J. of Fluids and Structures, vol. 5(1), pp. 33-45, Jan. 1991.

[14] Howe, M.S., "Noise produced by a sawtooth trailing edge”, J. Acoust. Soc. Am., vol. 90(1), pp. 482-487, 1991.

[15] Mayoral, S. and Papamoschou, D., "Effects of Source Redistribution on Jet Noise Shielding”, AIAA 2010-652, 2010.

[16] Papamoschou, D. and Mayoral, S., "Jet Noise Shielding for Advanced Hybrid Wing-Body Configurations", AIAA 2012-912, 2011.

[17] Hutcheson, Florence V. and Brooks, Thomas F., "Effects of Angle of Attack and Velocity on Trailing Edge Noise", International J. of Aeroacoustics, vol. 5(1), pp. 39-66, 2006.
[18] Podboy, G., “Jet-Surface Interaction Test: Phased Array Noise Source Localization Results", GT2012-69801, 2012.

[19] Brown, C. and Bridges, J., "Small Hot Jet Acoustic Rig Validation", NASA/TM-2006-214324, 2006.

[20] Bridges, J. and Brown, C., "Validation of the Small Hot Jet Acoustic Rig for Jet Noise Research", AIAA 2005-2846, 2005.

[21] Bridges, J. and Wernet, Mark P., "The NASA Subsonic Jet Particle Image Velocimetry (PIV) Dataset", NASA/TM-2011216807, 2011.

[22] Witze, P.O., "Centerline velocity decay of compressible free jets”, AIAA J. 12(4), 417-418, 1974.

This work is declared a work of the U.S. Government and is not subject to copyright protection in the United States. Approved for public release; distribution is unlimited. 